\title{
Los dos Alcaldes de Zalamea. Del texto primitivo a la obra de Calderón: Marco dramático y estructura teatral
}

\section{(The two Alcalde de Zalamea. From the primitive text to Calderón's work: Dramatic framework and theatrical structure)}

\author{
JESÚS FERNANDO CÁSEDA TERESA \\ casedateresa@yahoo.es \\ IES Valle del Cidacos-Calahorra (La Rioja)
}

Fecha de recepción: 20 de abril de 2019

Fecha de aceptación: 29 de julio de 2019

Resumen: En este estudio llevo a cabo un análisis comparativo del primitivo Alcalde de Zalamea, especialmente espacio, tiempo, personajes y marco dramático, con la obra de Calderón de la Barca. Encuentro que el primitivo texto tiene una estructura literaria heredera de la tradición cidiana que, sin embargo, no aparece en la obra de Calderón. Analizo asimismo la presencia de la ironía en el primer texto teatral, inexistente en el otro. Concluyo que hay, por todo ello, algunas diferencias en ambas obras en los aspectos señalados.

Palabras clave: Alcalde de Zalamea. Teatro Siglos de Oro. Calderón de la Barca. Cantar de Mio Cid.

\begin{abstract}
In this study I carry out a comparative analysis of the primitive Alcalde de Zalamea, especially space, time, characters and dramatic frame, with the work of Calderón de la Barca. I find that the primitive text has a literary structure inherited from the Cidian tradition which, however, does not appear in Calderón's work. I also analyze the presence of irony in the first theatrical text, which does not exist in the other. I conclude that there are, therefore, some differences in both works in the aspects indicated.
\end{abstract}

Keywords: Alcalde de Zalamea. Golden Age Theater. Calderón de la Barca. Cantar de Mio Cid.

\section{Antecedentes}

Es algo muy conocido que la obra de Calderón, también llamada El garrote más bien dado en su primera edición (1651), toma buena parte del argumento, 


\section{JESÚs FERNANDo CÁSEDA TERESA}

personajes e incluso versos enteros del primitivo texto teatral El alcalde de Zalamea, que durante mucho tiempo se vino atribuyendo a Lope de Vega. Hoy, quizás, Calderón habría sido objeto de un procedimiento judicial. Cierto es que, en descargo de Calderón, la obra primitiva dejó a muchos indiferente y, sin embargo, la suya tuvo un éxito importante desde su estreno. El éxito de la adaptación calderoniana superó al del texto original y el resultado es evidente, al haberse convertido en una de las obras más importantes de la dramaturgia en lengua castellana de todos los tiempos.

Aunque durante mucho tiempo se ha venido atribuyendo, como ya he señalado, su composición a Lope de Vega, participante en la acción naval de la isla Terceira, en 1582, bajo el mando naval de D. Álvaro de Bazán, contra las tropas francesas del almirante Felipe Strozzi, últimamente algunos críticos han considerado que El alcalde de Zalamea original o primitivo es obra de Andrés de Claramonte (Rodríguez López-Vázquez 2014), un interesante escritor, actor y atrabiliario personaje de orígenes murcianos que, como muchos de su oficio, llevó una vida itinerante a lo largo de toda la geografía nacional. La tesis es sostenida por el profesor Alfredo Rodríguez López-Vázquez, quien ha estudiado la figura de Claramonte en diversos trabajos de investigación (1983, 1987a y 1987b); autor a quien el mismo investigador ha atribuido también El burlador de Sevilla.

En la misma línea se encuentran algunos trabajos de Cantalapiedra (1990 y 1993). Y, frente a ellos, con opiniones divergentes, Vázquez (1985: 397-429; 1987: 9-50).

Las razones que esgrime Rodríguez López-Vázquez son de orden fundamentalmente lingüístico (repetición de expresiones en la obra y en otras atribuidas a Claramonte), de orden compositivo y métrico, expuestas con criterio y gran rigor científico en la introducción a su reciente edición de la obra. Señala, a este respecto, la presencia del seseo a lo largo de ella, tal y como conocemos ocurría con otras obras del murciano. Tales índices lingüísticos y métricos, a su parecer, están muy lejos de los habituales de Lope de Vega y ponen a El alcalde de Zalamea más cerca de Andrés de Claramonte que del escritor madrileño.

Rodríguez López-Vázquez cree que la obra debió de escribirse en fechas cercanas a 1615, año de publicación de la segunda parte del Quijote cervantino, dadas algunas relaciones que encuentra entre ambas, especialmente en las sentencias dictadas por Sancho como gobernador de la ínsula Barataria y las de Pedro Crespo.

No es objeto de este estudio afirmar o rebatir la tesis del citado investigador, la cual ha sido defendida con convincentes argumentos de carácter lingüístico y filológico por el mismo. Ya antes, otros mostraron importantes reticencias a la 
Los dos Alcaldes de Zalamea. Del texto primitivo a la obra de Calderón...

autoría de Lope de Vega, por ejemplo, Elizabeth I. Trexler (2009), quien, aun sosteniendo que la obra es de Lope, no dejó de manifestar los problemas de una obra escrita con celeridad como se puede apreciar en la abundancia de equivocaciones:

El Alcalde es una de las más débiles e inestables del dramaturgo. Lo más probable es que por esta misma razón, se mantenía y hoy día todavía se mantiene hasta cierto punto en el olvido debido a la celeridad creadora del Fénix y las equivocaciones que sufrió a causa de esta producción rápida y espontánea. A causa de eso, estos críticos se han ocupado de la pieza solamente para referirse a la importancia que tiene la comedia lopesca como fuente y esbozo de la comedia de Calderón en la que los personajes, especialmente el de Pedro Crespo, alcanzan una mayor hondura psicológica y dramática (Trexler, 2009: 3-4).

Morley-Bruerton (1968: 411-412) pusieron también claras reticencias a la autoría lopesca, tras un análisis de la rima y estructuras métricas de la obra. También Arjona (1956: 290-305) expresó objeciones aludiendo, por ejemplo, a la presencia de ceceo y seseo en la misma, algo ajeno al teatro del madrileño Lope de Vega. Y George Peale (1996: 27-62) atribuyó a Vélez de Guevara su autoría.

El objeto del estudio que ahora principio, sin embargo, se limita a comparar ambas obras en los siguientes aspectos: marco espacial, temporal, personajes y estructura compositiva. Cierto es que ya existen algunos trabajos, pocos, y quizás incompletos, sobre este objeto. A este respecto, Martínez Bennecker (2013), superando el veterano trabajo de Kernsten (1972: 263-273) ha llevado a cabo un estudio comparativo de ambas obras, de Lope y Calderón. Sigue siendo estimable, en el análisis de ambas, el de Touron (1981: 534-550), pese a los muchos años transcurridos. Contamos con dos ediciones "dobles" de El alcalde de Zalamea, por J. Alcina Franch (Calderón 1970) y Juan M. Escudero (Calderón 1998). Y una reciente solo de la obra "primitiva" (Rodríguez López-Vázquez 2014).

Todos ellos han entendido la necesidad de llevar a cabo una comparación entre ambas obras, sobre todo cuando creían poder contraponer a nuestros dos mayores autores teatrales — Lope y Calderón — tratando un mismo asunto, con casi los mismos personajes y bajo una parecida estructura teatral. El descubrimiento de la posible autoría de Claramonte ha trastocado todo ello. Sin embargo, y por encima de la comparación de los autores, la llevada a cabo sobre ambas obras nos pone ante los orígenes de la obra, el Alcalde de Zalamea, que este 


\section{JESÚS FERNANDO CÁSEDA TERESA}

trabajo estudia bajo una perspectiva no solo literaria, sino también histórica. Esta perspectiva historicista intenta, por ello, explicar la génesis de ambas obras y las diferenciasen los aspectos que a continuación señalo.

Lo que este estudio pretende, en definitiva, y a diferencia de los trabajos antes referenciados, es descubrir los diferentes espacios en que se sitúan, a partir de la documentación archivística que he manejado. Y ello trae, en nuestro caso, consecuencias de orden temporal, pues ambas obras dramáticas sitúan la acción en tiempos históricos diferentes, como luego indico, toda vez que también el espacio es distinto.

Encuentro, en cuanto a la articulación de los personajes, que la primitiva obra tiene un carácter mucho más irónico que la segunda y que Calderón, simplificando el número de personajes, consigue una mayor profundización en la caracterización de los mismos.

En cuanto a la estructura dramática, la obra primitiva es más fiel a ciertas tradiciones literarias, especialmente cidianas, mientras que Calderón se desvincula completamente de aquellas y articula un discurso teatral mucho más elaborado.

A este respecto, la escritura un tanto improvisada de la obra primitiva que apunta, como he indicado, Elizabeth I. Trexler (2009), quizás tenga como causa, el tratarse de un encargo, siempre sometido a unos plazos de entrega y a cierta premura en su elaboración. En cualquier caso, los errores que podemos encontrar en el texto primitivo y que señala la citada investigadora no son habituales en Lope de Vega, pese a su corta edad, con apenas veinte años cuando intervino en los hechos bélicos de las Azores (1583), con calidades de notable dramaturgo ya desde la primera obra que parece escribió, su infantil Comedia de los Hechos de Garcilaso de la Vega y moro Tarfe, compuesta con apenas doce. No obstante, no puedo aportar un documento original que atestigüe o demuestre la existencia de dicho encargo que, sin duda, podría explicar algunas cuestiones relevantes del texto primitivo, siendo mi hipótesis una pura especulación.

\section{El espacio en El alcalde de Zalamea}

La obra primitiva y la de Calderón se desarrollan en Zalamea, sin especificar en cuál de ellas. Entonces, en la época en que se sitúan las obras, años ochenta del siglo XVI, existían, como ahora, dos Zalameas: Zalamea de la Serena, en el sur de la actual provincia de Badajoz; y Zalamea — todavía entonces no apellidada "la Real" - en la provincia de Huelva. Tradicionalmente, se ha considerado que se trata de la primera; puesto que los hechos que se cuentan se desarrollaron históricamente en Extremadura, concretamente en la provincia de Badajoz, donde durante meses se fue formando un ejército que finalmente entró en Portugal en la primavera de 1580, para hacer valer los derechos de Felipe II al 
Los dos Alcaldes de Zalamea. Del texto primitivo a la obra de Calderón...

trono. La llegada del rey a Badajoz, donde fue recibido en vísperas de la acción del ejército en el país vecino (Valladares 2008), contribuye a situar la acción en Zalamea de la Serena.

Sin embargo, hay algunos datos que permiten albergar alguna duda. Manuel Fernández Álvarez (1999: 218) sitúa la acción de la obra en Zalamea la Real sin dar ninguna razón al respecto. En la de Calderón se afirma que Lope de Ulloa viene de Guadalupe (en Extremadura) y que la mayor parte de las tropas proceden de Llerena, cercana a Zalamea de la Serena. Calderón, sin duda, sitúa la acción en dicha localidad. Pero en el primitivo texto parece que las tropas, acabada la llamada campaña de Portugal, se dirigen, por orden de Felipe II, a la expedición de la isla Terceira, en las Azores, bajo mandato de Lope de Ulloa, desde Andalucía. En este texto aparece un personaje llamado Bartolo el de Berrocal, localidad esta próxima a Zalamea la Real, en la actual provincia de Huelva. Hay, además, una circunstancia que, tal vez, no sea simple coincidencia: durante el tiempo de la campaña portuguesa, Felipe II despacha diversos documentos por los que la población deja de ser villa arzobispal y pasa a ser realengo; de ahí el apellido "la Real" que se concederá casi coincidiendo históricamente con los hechos que aparecen en la obra ${ }^{1}$.

A este respecto, planteo una hipótesis: ¿Pudo el concejo encargar al autor del primitivo texto una obra de teatro - algo muy habitual entonces - para celebrar el otorgamiento del estatuto de realengo? La presencia del rey Felipe II en la obra apoyaría tal hipótesis y el coincidente cambio de nombre: de simplemente Zalamea, a Zalamea "la Real". Sin embargo, Calderón no se apercibió de dicha circunstancia y situó la acción en la localidad extremeña.

Por otra parte, sabemos que en Zalamea la Real hubo en aquel tiempo un alcalde ordinario llamado Juan Serrano ${ }^{2}$, cuyo nombre aparece en el texto primitivo. Y también conocemos que, en 1582, un juez comisionado por el rey pretende arrebatar al alcalde, entonces Alonso Pérez León, su vara de mando, oponiéndose este y defendiendo los derechos de su pueblo frente a dicha afrenta.

\footnotetext{
${ }^{1}$ No obstante, todavía en 1582 aparece designada como solo Zalamea, sin el calificativo de "la Real". Así aparece en un documento que he localizado en el Archivo Histórico Nacional: "Ejecutoria dada a instancia del concejo de la Mesta del pleito con el Concejo de la villa de Zalamea, mandando que permita el libre paso de los ganados de la Mesta por sus términos". ES.28079.AHN/1.2.3.5//DIVERSOS-MESTA,234,N.2

2 Varios estudiosos de la localidad onubense, en la dirección disponible en línea en: http://zalamealareal-historia.blogia.com/ dan cuenta de la existencia de dicho Juan Serrano, "personaje cuya existencia real está documentada en Zalamea, en el Libro de los Privilegios, primero como regidor y después como alcalde, precisamente en el periodo en el que se sitúan los hechos (1580 - 1583)" [Fecha de consulta: 7 de septiembre de 2018].
} 


\section{JESÚS FERNANDO CÁSEDA TERESA}

González (1952: 12 y ss.) supone que Alonso Pérez León fue el real alcalde de Zalamea, sobre cuya biografía se creó la obra calderoniana.

Se ha debatido sobre la etimología de Zalamea, palabra de origen árabe (salamiya), cuyo significado es 'saludable'3. Sin embargo, existe una etimología que se ha transmitido de generación en generación, falsa y no apoyada en ningún dato documental excepto en la cercanía de sonidos: el nombre procedería, según diversas leyendas, del Salomón bíblico. De tal modo, es muy probable que en la época de Lope existiera esta falsa etimología que aproximaría a la localidad al rey y sabio juez del libro sagrado. Es posible que el primer autor, o cualquiera de su tiempo, supiera de esta relación de la localidad con la idea de impartición de justicia y aprovechara tal eventualidad para el dibujo de un Pedro Crespo alcalde justiciero; algo que se corrobora, como luego veremos, con el propio nombre del alcalde.

\section{El tiempo histórico}

Es bastante probable que, localizadas ambas obras en diferentes lugares (Zalamea la Real en el primer texto; Zalamea de la Serena en el de Calderón) y ambos espacios situados en los recorridos de los tercios de Felipe II en momentos sucesivos, tengamos que concluir que los tiempos históricos de ambas obras son distintos.

En virtud de lo anterior, la acción del texto calderoniano hemos de situarlo en 1580, en fechas anteriores a la entrada en Portugal. Y el texto primitivo en 1582, dos años después, tras la campaña portuguesa, de camino de Andalucía a Portugal, para embarcar hacia las Azores, en concreto a la Isla Terceira, desde el puerto de Lisboa.

En cualquiera de los dos casos, ambas obras soslayan las cruentas acciones de guerra que se desarrollaron en los dominios portugueses. En un caso, en la batalla de la isla Terceira, murieron cerca de 2000 soldados franceses y 225 españoles. Y en la campaña peninsular los soldados del duque de Alba practicaron, especialmente en Lisboa, una represión en algunos momentos brutal contra cualquier signo de oposición a la anexión española. Los datos que ofrece Henri

3 Según Gordón: “Zalamea. Asín Palacios propone para éste y el nombre pacense homónimo un étimo árabe con significado 'saludable', que hay que calificar de muy extraño semánticamente. Quizá sea preferible relacionar el nombre con el antropónimo árabe Saláma y con los topónimos Zulema (español) y Zoleima, Zalema, Zalama, Salama y Culeima (portugueses) que recuerda David Lopes". "Análisis etimológico de la macrotoponimia onubense". Disponible en línea en: rabida.uhu.es/dspace/bitstream/handle/10272/2924/b15138677.pdf?sequence $=1$. [Fecha de consulta: 7 de septiembre de 2018]. 
Los dos Alcaldes de Zalamea. Del texto primitivo a la obra de Calderón...

Forneron (1884: 284 y ss.) de la campaña portuguesa en su libro Historia de Felipe II son bastante esclarecedores a este respecto.

Nada de ello, sin embargo, percibimos en ninguna de las dos obras de teatro. Parece que los dos autores hubieran hecho voto de ocultar la crudeza de la campaña militar. Algo por otra parte lógico, puesto que, en realidad, solo sirve de marco histórico sin ningún otro desarrollo argumental dentro de las dos piezas.

\section{Los personajes de la obra}

Calderón respeta el nombre de algunos de los personajes más relevantes del texto primitivo de El alcalde de Zalamea, aunque hay algunos cambios de relevancia que luego he de señalar. El protagonista Pedro Crespo ya aparece en el Guzmán de Alfarache como simple referencia y no como personaje propiamente dicho:

Acuérdome que un labrador en Granada solicitaba por su interese un pleito, en voz de concejo, contra el señor de su pueblo, pareciéndole que lo había con Pero Crespo, el alcalde dél, y que pudiera traer los oidores de la oreja. Y estando un día en la plaza Nueva mirando la portada de la Chancillería, que es uno de los más famosos edificios, en su tanto, de todos los de España, y a quien de los de su manera no se le conoce igual en estos tiempos, vio que las armas reales tenían en el remate a los dos lados la Justicia y Fortaleza. Preguntándole otro labrador de su tierra qué hacía, por qué no entraba a solicitar su negocio, le respondió: «Estoy considerando que estas cosas no son para mí, y de buena gana me fuera para mi casa; porque en ésta tienen tan alta la justicia, que no se deja sobajar, ni sé si la podré alcanzar.» No es maravilla, como dije, y lo sería, aunque uno la tenga, no sabiendo ni pudiéndola defender, si se la diesen. A mi padre se la dieron porque la tuvo, la supo y pudo pleitear; demás que en el tormento purgó los indicios y tachó los testigos de pública enemistad, que deponían de vanas presunciones y de vano fundamento (Alemán 1996: 82).

En las anteriores líneas, Mateo Alemán separa los dos niveles más importantes de la justicia de su época: uno cercano al pueblo encarnado en Pedro Crespo, alcalde ordinario de su localidad; y otro, la justicia de las audiencias y Chancillería, con sus jueces y oidores. El labrador del pueblo de Granada, llegado a esta última, desecha la posibilidad de continuar su pendencia porque entiende que esta justicia 


\section{JESÚS FERNANDO CÁSEDA TERESA}

está demasiado alta y no la podría alcanzar. En otros términos: no se trata solo de tener la razón, sino de contar también con dinero para defenderla, con buenos abogados, fortaleza, suerte, etc.

Pedro Crespo, en el texto de Mateo Alemán, encarna una clase de justicia accesible al pueblo, comprensible, gratuita y aceptada mayoritariamente, lejos de las instancias superiores, con su fárrago leguleyo incomprensible y carísimo.

Es evidente, por tanto, que el nombre del personaje Pedro Crespo se asocia, ya en la obra de Mateo Alemán, a dos ideas: alcalde de pueblo y justicia popular. En igual sentido, aparecerá en el Pedro de Urdemalas cervantino el personaje de Martín Crespo, alcalde y padre de Clemencia, retratado como alcalde y hombre justo en sus dictámenes. El origen popular del nombre de Pedro Crespo no es, sin embargo, tan claro como el de Pedro de Urdemalas o el de Juan Ramos, entre otros, recogidos en abundantes textos orales y escritos de tradición popular. Cierto es que alguno existe, como este de tierras riojanas - Alfaro- que dice así:

En Zaragoza entré y por Pedro Crespo Calvo carpintero pregunté y me dijo una mujer: -¿Por qué Pedro Crespo Calvo carpintero pregunta usted? ¿Por un Pedro Crespo Calvo carpintero, el de arriba, o por Pedro Crespo Calvo carpintero el de abajo, o por Pedro Crespo Calvo carpintero el del arrabal? Porque aquí hay tres Pedros, Crespos, Calvos, carpinteros, en este lugar, que no quieren trabajar ${ }^{4}$.

He localizado, en fechas anteriores, próximas a los hechos que se cuentan en el primitivo Alcalde de Zalamea, algunos Crespo encausados en Llerena, cabeza de partido judicial de Zalamea de la Serena: En una "Relación de procesados por delitos de fe pertenecientes al Tribunal de la Inquisición de Llerena que se despacharon desde 20 de mayo de 1589 hasta 20 de mayo de 1590, y estado de sus causas" encontramos a un Diego Crespo, procesado por "proposiciones heréticas"5.

En cualquier caso, es evidente que el protagonista de El alcalde de Zalamea encarna, mejor que nadie, la justicia popular y los valores de nobleza del pueblo a que representa.

Como indica Felipe Lorenzana de la Puente (2003: 32):

\footnotetext{
4 Disponible en línea en: http://www.riojarchivo.com/los-tres-pedros-crespos-calvoscarpinteros/. [Fecha de consulta: 7 de septiembre de 2018].

${ }^{5}$ Archivo Histórico Nacional. Signatura. ES.28079.AHN//INQUISICIÓN,1987,Exp.15
} 
Los dos Alcaldes de Zalamea. Del texto primitivo a la obra de Calderón...

El Rey era la fuente de toda jurisdicción, y ésta era ejercida territorialmente por sus representantes (consejos, chancillerías y audiencias, corregidores, alcaldes mayores y alcaldes ordinarios), conformando así el entramado de la justicia ordinaria.

Los alcaldes ordinarios eran la máxima autoridad de las villas que no eran cabeza de partido, según Felipe Lorenzana. Este señala que:

El intervencionismo regio no contaba aquí con corregidores, gobernadores o alcaldes mayores, y aunque el aliento de éstos se sentía a no mucha distancia — sus instrucciones les obligaban a mirar por los intereses del rey en todo el partido, y su concurso como letrados era necesario para paliar la deficiente formación jurídica de los alcaldes ordinarios-, lo cierto es que la libertad con la que éstos actuaron y las prerrogativas que ejercieron fueron mucho más amplias de lo que se ha creído. Contribuía a ello el favor popular, tantas veces movilizado y otras arruinado por defender la integridad de la jurisdicción local, aunque la misma estuviese monopolizada por la oligarquía (Lorenzana 2003: 33).

Para ser alcalde ordinario, como Pedro Crespo, no era necesario tener muchas cualidades:

Las leyes establecían muy pocos requisitos físicos e intelectuales para ser alcalde (no ser sordo, ciego, mudo, enfermo crónico, loco ni imbécil), ni siquiera se obligaba expresamente a saber leer y escribir. Sí existían los habituales condicionamientos sociológicos y profesionales, y el hecho es que éstos bastaban para excluir a la mayoría de la población de los núcleos objeto de este estudio: arrendadores de alcabalas y de escribanías, clérigos, mesoneros, tejedores, carpinteros, buhoneros, carniceros, albañiles, tundidores, barberos, alfayates, requeros, jornaleros de cualquier tipo, los que tuvieran deudas con el Concejo o con el clero de más de 300 mrs. y los pobres (Lorenzana 2003: 39).

De hecho, Pedro Crespo no sabe leer, lo cual reconoce con cierto orgullo. La causa es muy evidente: muchos procesados por la Inquisición eran conversos, 


\section{JESÚS FERNANDO CÁSEDA TERESA}

con buena formación intelectual, con estudios, que no tenían la condición de cristianos viejos. De manera que, incluso para el imaginario popular, no saber leer ni escribir era un indicio de tener orígenes no manchados.

En el texto primitivo, Pedro Crespo tiene dos hijas, de nombres Inés y Leonor. Es evidente que el nombre de esta última - Leonor - guarda relación con la honra o el honor, tema fundamental de la obra, que luego se repetirá a lo largo de muchas de las de Lope y Calderón. Y el significado etimológico de Inés es también muy claro: su origen es griego, agné, agnes en su forma latina, y su significado es 'aquella que es casta y pura' o 'aquella que se mantiene pura' (Tibón 1956: 271). Se trata, evidentemente, de una forma irónica, al igual que en el caso de su hermana Leonor, quien también perderá, como aquella, su honra y su pureza o castidad a manos de los dos capitanes Juan y Diego, de los tercios del ejército español.

En el texto de Calderón, aparece solo una hija —-Isabel—, que muestra una actitud mucho más recatada que las dos hermanas. Inés y Leonor son engañadas por los dos capitanes; pero ambas consienten y buscan una relación amorosa con ambos, en una forma mucho más activa que en el texto calderoniano, donde Isabel es asaltada y violada por Álvaro de Ataide.

Los dos capitanes de la obra primitiva, los citados Juan y Diego, de origen noble, desprecian a las plebeyas hijas de Pedro Crespo y por tanto desprecian al propio alcalde ordinario de Zalamea. Para ellos se trata de una simple aventura amorosa con unas campesinas de una aldea perdida en un rincón de la península. Conocemos perfectamente el nombre de todos los capitanes que participaron en la campaña portuguesa, recogidos en el libro de Julián Suárez Inclán Guerra de anexión en Portugal durante el reinado de don Felipe II. Entre los citados, he localizado a dos que probablemente eran hermanos, de nombre Juan Fernández de Córdoba, capitán del tercio de Antonio Moreno y el capitán Diego de Córdoba, del mismo tercio, los únicos posibles hermanos capitanes de los seis tercios movilizados en la campaña (Suárez 1898: 375). Quizás ambos son los aludidos en la obra. Lo digo con absoluta prevención y suponiendo que el autor del primitivo texto tuviera una fuente de información muy fiel sobre la guerra y los nombres de dichos capitanes. En todo caso, no deja de ser curiosa la coincidencia de los nombres de los capitanes del primitivo Alcalde de Zalamea y de los dos capitanes de los tercios españoles que he señalado y que participaron en la anexión de Portugal a partir de 1580. ¿Se trata de una suerte de ironía como en el caso del nombre de las hijas de Pedro Crespo? El apellido de los dos capitanes documentados en la guerra contra Portugal, Fernández de Córdoba, nos recuerda al Gran Capitán y, en la época, nombrar al Gran Capitán suponía reverenciar y bendecir su recuerdo, sus gestas innumerables y su valor y heroicidad. Sin 
Los dos Alcaldes de Zalamea. Del texto primitivo a la obra de Calderón...

embargo, los capitanes Juan y Diego son exactamente lo contrario: cobardes, viles con las hijas de Pedro Crespo y crueles con los habitantes de Zalamea.

En la obra calderoniana, nuevamente se simplifica el número de personajes que, en lugar de dos — capitanes Juan y Diego- pasa a ser uno, el capitán D. Álvaro de Ataide. Según Markus Wiensberger,

Se trata de un nombre muy conocido en la época, de un hijo de Vasco da Gama que oficiaba de gobernador de Malaca. Adquirió pésima fama por negarle el permiso a un diplomático portugués a acompañar a la China a Francisco Javier, el famoso misionero jesuita. Por esta razón, éste no pudo viajar y murió de frustración, como se decía. Ataide fue condenado a la picota y a prisión ${ }^{6}$.

Con anterioridad a este, existió un personaje histórico portugués del mismo nombre, nacido hacia 1430 y probablemente fallecido a finales del siglo XV, cien años antes de los hechos que se cuentan en El alcalde de Zalamea calderoniano. Este noble portugués fue señor de Peñacova y participó con los españoles en la guerra contra los moros (Salazar 1585: 238). He localizado finalmente un Álvaro de Ataide en la colección bibliográfica de José Simón Díaz, autor de una obra titulada El gran padre de los creyentes, Abraham [...], publicada en Madrid en 1636 (Simón Díaz 1996: 67 del vol. 16). Desconozco la identidad de tal sujeto —el Álvaro de Ataide citado por Simón Díaz-, a quien pudo conocer Calderón. Aunque creo más factible que tomara el nombre del capitán de su obra del noble portugués a que se refiere Markus Wiensberger, quizás en venganza por la oposición portuguesa a los derechos dinásticos que exhibió Felipe II queriendo evitar una guerra que, finalmente, se produjo a pesar de sus esfuerzos diplomáticos. Tal vez Calderón obrara una forma de venganza poética o teatral poniendo como principal antagonista de Pedro Crespo a un noble portugués que se opuso a los deseos del misionero san Francisco Javier.

El personaje más cercano al alcalde Pedro Crespo es Juan Serrano. Ya me he referido con anterioridad a la existencia de un individuo del mismo nombre contemporáneo de los hechos que se cuentan en el primitivo Alcalde de Zalamea, alcalde ordinario de Zalamea —luego Zalamea la Real— perfectamente documentado. Quizás se basó en él el primer autor para dar forma a Pedro Crespo y tal vez le hizo un homenaje introduciéndolo en la obra con su propio

6 "El alcalde de Zalamea y los conceptos del orden y de la justicia". Disponible en línea en: http://www.markus-wirnsberger.de/media/dd6aed4aa15b4b71ffff8b3cac144225.pdf. [Fecha de consulta: 7 de septiembre de 2018]. 


\section{JESÚS FERNANDO CÁSEDA TERESA}

nombre, aunque sin el protagonismo de Pedro Crespo ni el cargo de alcalde que él mismo ostentó entonces.

Por otra parte, también he localizado en los archivos de la época a un Juan Serrano, de Zalamea, condenado por morisco en $1587^{7}$. Desconozco si se trata del mismo personaje, aunque resultaría muy curioso que en el origen del alcalde Pedro Crespo - símbolo del honor y de la honra- se encontrara un morisco. Y ello no sería tan sorprendente habida cuenta de la ironía de los nombres de sus hijas: Inés (o la castidad) y Leonor (o la honrada). O habida cuenta de la posibilidad de que tras los capitanes Juan y Diego se ocultasen los apellidos del Gran Capitán.

En ambas obras, aparece Lope de Figueroa, personaje histórico muy conocido en la época, participante en la batalla de las Azores. Sin embargo, en el texto primitivo apenas cobra protagonismo, frente al texto calderoniano, donde tiene parlamentos más largos y una intervención en el hilo argumental más intensa. No obstante, el carácter del personaje en ambas obras es muy semejante: honrado, disciplinado, enérgico y fiel a la legalidad, defensor de sus soldados y de la jurisdicción militar, del propio rey y de la justicia. De la presencia de Lope de Figueroa en algunas obras de teatro del XVII, como personaje recurrente, se ha ocupado Juan Manuel Escudero Baztán (2014: 259-274) y Hendriks (1983: 703-708). Sobre el personaje histórico, Leonardi (2013: 273-284).

Hay un detalle de relevancia en el tratamiento de este personaje en la primitiva obra, la alusión repetida a sus problemas con las piernas y los ataques de gota que también aparecen en la obra de Calderón siguiendo el ejemplo de aquellay que vemos de forma insistente en la obra de Lope de Vega El asalto de Mastrique por el duque de Parma, donde es asimismo Lope de Figueroa víctima de fuertes dolores en sus piernas.

\section{La estructura cidiana de $E 1$ alcalde de Zalamea primitivo}

$\mathrm{Si}$, por lo que ya voy señalando, no es difícil deducir una cierta intención irónica en la onomástica y en la referencialidad de los personajes más relevantes del primitivo Alcalde de Zalamea, también podemos encontrar una claro referente en la estructura argumental de dicha obra, la tradición cidiana.

\footnotetext{
7 "Relación de procesados por delitos de fe pertenecientes al Tribunal de la Inquisición de Llerena despachados en la visita realizada por el inquisidor visitador Rodrigo de Mendoza en Plasencia, Mirabel, Serradilla, Casas de Millán, Grimaldo, Torrejón, Las Corchuelas, Oliva, El Villar, Cabezabellosa, La Jarilla, Segura, Casas del Monte, Gargantilla, Aldeanueva del Camino, Gargüera, El Barrado, Rebollar, El Torno, Valdeastillas, Arroyomolinos y Tejeda el año 1587, y estado de sus causas". Archivo Histórico Nacional. Signatura: ES.28079.AHN//INQUISICIÓN,1988,Exp.22.
} 
Los dos Alcaldes de Zalamea. Del texto primitivo a la obra de Calderón...

Sin duda, pocos personajes históricos fueron tan tratados en los romances como Rodrigo Díaz de Vivar — el Cid Campeador — desde el siglo XV, siguiendo las crónicas medievales y diversas leyendas y tradiciones orales. El teatro de los siglos de Oro reparó pronto en la figura de Mio Cid y produjo un número importante de piezas que se representaron exaltando al glorioso héroe castellano. Germán Vega García-Luengos ha analizado su influjo en veintidós piezas teatrales de los siglos de Oro. Según este último:

A la postre, la materia cidiana ha servido para experimentar
teatralmente y ha mostrado con su evolución los aspectos
polifónicos que conforman la época barroca, su propensión
a la variedad y a la variación. Y, de paso, se ha ofrecido
como palestra ideal para la competición entre dramaturgos
dispuestos a mostrar su capacidad de superar al contrario ${ }^{8}$.

El mayor estudioso vivo del Poema de Mio Cid, el profesor de la Universidad de Zaragoza Alberto Montaner Frutos, ha señalado, también la importancia que tuvo el Cid en el teatro español de los siglos de Oro (Montaner 1981: 121 y ss.). También Ignacio Arellano (2007). Sin embargo, nadie parece haberse apercibido de la intrínseca relación que mantiene El alcalde de Zalamea primitivo con el Poema de Mio Cid.

La primera pregunta sería, ¿por qué? Esto es, ¿por qué el primer autor crearía una obra teatral a principios del XVII siguiendo el modelo de la obra cidiana? Quizás porque nadie mejor que Rodrigo Díaz de Vivar representa las ideas de honor y de honra. Sin duda, el Cid Campeador se convirtió en el primer modelo de castellano viejo, honrado, valiente y fiel a los principios de la rectitud y de la nobleza a ojos de los escritores del XVII.

Hay un hecho, quizás casual, que coincide con la escritura del primitivo Alcalde de Zalamea. En 1596, Juan Ruiz de Ulibarri y Leyva encuentra el manuscrito del Poema de Mio Cid en el monasterio de Santa Clara, en Vivar (Burgos). El promotor del descubrimiento del manuscrito burgalés fue Gil Ramírez de Arellano, importante personaje del XVI, miembro del Consejo de Castilla y tío de Luis y Juan Ramírez de Arellano, el "Gran Memoria" y el "Memorilla"9. D. Gil había

8“El Cid en el teatro del Siglo de Oro español. Las múltiples caras de una figura persistente". Disponible en línea en:

https://uvadoc.uva.es/bitstream/10324/3756/1/Libro\%20CID.\%20Cap\%202\%20G.Vega.pdf. [Fecha de consulta: 7 de septiembre de 2018].

9 "El Cid en el teatro del Siglo de Oro español. Las múltiples caras de una figura persistente".

Disponible en línea en: 


\section{JESÚS FERNANDO CÁSEDA TERESA}

enviado a Juan Ruiz de Ulibarri a recorrer diversos archivos y depósitos documentales a la búsqueda de pruebas de sus orígenes nobles, tanto en Navarra, como en La Rioja y en Burgos, y de ahí resultó el hallazgo del manuscrito cidiano. El noble Gil Ramírez de Arellano elaboraría con dichos documentos un trabajadísimo estudio genealógico o prueba de limpieza de sangre que servirá de modelo para otros muchos que luego se hicieron. En dicho estudio o memorial familiar, D. Gil afirma proceder de la familia real navarra y ser descendiente por tanto del propio D. Rodrigo Díaz de Vivar. De ello pudieron hacer gala sus descendientes, a mayor gloria de una estirpe antigua y noble.

¿Fue conocedor el autor del primitivo Alcalde de Zalamea de tal descubrimiento? Lo desconozco, pero no deja de ser curiosa la coincidencia en las fechas del hallazgo del manuscrito y posterior copia por Ulibarri y la escritura de El alcalde de Zalamea. Ciertamente, no he podido documentar que Claramonte conociera tal descubrimiento, aunque es evidente que tal circunstancia pudo ayudar a incrementar un interés por su figura que fue constante a lo largo de todo el siglo XVII, como luego veremos. En todo caso, encontramos la alusión a las hijas del Cid y a este mismo en la obra primitiva (vv. 1417-1424). Lo que no ocurre, sin embargo, en el texto calderoniano.

El texto de El alcalde de Zalamea primitivo se organiza siguiendo una estructura, tanto de personajes como temática, muy parecida al del Poema de Mio Cid. En un caso, D. Rodrigo Díaz de Vivar tiene dos hijas (Elvira y Sol); y, en el otro, Pedro Crespo a Leonor e Inés. Tanto D. Rodrigo como Pedro Crespo son personas honradas, queridas por sus gentes y sin unos orígenes sociales o estamentales elevados. D. Rodrigo, como infanzón, forma parte de la clase más baja de la nobleza. Y D. Pedro Crespo, aunque rico, no deja de ser un campesino.

Ambos personajes (D. Rodrigo y Pedro Crespo) actuarán en las dos obras con justicia y siguiendo los dictados del honor y de la honra. Y ambos sufrirán parecidos embates por dos yernos que casan con sus hijas: los infantes de Carrión y los capitanes Juan y Diego. Estos yernos son de orígenes nobles, muy superiores a los de D. Rodrigo en un caso y a los de Pedro Crespo en el otro. Pero ambos yernos se convierten en antagonistas de los dos personajes principales del Poema de Mio Cidy de El alcalde de Zalamea.

¿La causa? Los infantes de Carrión deshonran a $\mathrm{D}^{\mathrm{a}}$ Elvira y a $\mathrm{D}^{\mathrm{a}}$ Sol, y los capitanes de El alcalde de Zalamea hacen lo propio con Inés y Leonor, cuyos nombres tienen un origen claramente irónico. Cierto es que las dos primeras tienen una relación mucho más pasiva con sus esposos que las dos últimas, como

https://uvadoc.uva.es/bitstream/10324/3756/1/Libro\%20CID.\%20Cap\%202\%20G.Vega.pdf. [Fecha de consulta: 7 de septiembre de 2018]. 
Los dos Alcaldes de Zalamea. Del texto primitivo a la obra de Calderón...

ya he señalado. Pero en los dos casos el deshonor alcanza no solo a ellas sino también a sus padres y, por tanto, a su propia familia.

Hay una curiosa coincidencia entre las dos obras. En el Poema de Mio Cid, $\mathrm{D}^{\mathrm{a}}$ Elvira y $\mathrm{D}^{\mathrm{a}}$ Sol serán atadas desnudas a un roble en el tercer cantar o de la afrenta del Corpes. Y en El alcalde de Zalamea será atado, también a un roble - la referencialidad es clara- el alcalde Pedro Crespo por unos soldados. No puede ser casualidad: el primer autor está haciendo un guiño al lector y a la obra cidiana al elegir, de entre todas las clases de árboles, el roble. Geográficamente, el árbol que más abunda en la zona del sur de Badajoz y Huelva es el alcornoque; mientras que el roble es un árbol característico del norte peninsular. Pero al autor no le importa que ocurra tal incoherencia puesto que se trata de seguir el modelo cidiano.

En los dos casos —Poema de Mio Cid y El alcalde de Zalamea- se impone la venganza por la deshonra sufrida, con el fin de limpiar la afrenta. No importa en ninguno de los dos que sean personas de estatus social muy superior (infantes reales/capitanes) ni que existan jurisdicciones especiales (el propio rey en un caso o la jurisdicción militar a que apela Lope de Figueroa en el otro) porque tanto el Cid, a través de sus dos mejores soldados, como Pedro Crespo a través del poder conferido por su pueblo como alcalde ordinario llevan a cabo la venganza y dan fin a personajes viles e innobles no por su sangre, sino por sus actos. La justicia poética presente en el Poema de Mio Cid y la que encontramos en El alcalde de Zalamea son muy parecidas.

En las dos obras, el rey (Alfonso VI/Felipe II) acepta la resolución tanto del Cid como del alcalde Pedro Crespo, sancionándola e incluso premiándola. Rodrigo Díaz de Vivar casará a sus dos hijas, doña Elvira y doña Sol, con los infantes de Navarra y Aragón, cruzando su sangre con la del propio rey. Y Pedro Crespo será premiado por Felipe II con el otorgamiento de la alcaldía perpetua de Zalamea. Ambos reyes quedan a salvo de las iniciales sospechas de haber participado en la muerte de su hermano el rey Sancho II a mano de Bellido Dolfos —en el caso de Alfonso VI- o de apoyar a personas de origen noble — probablemente descendientes del Gran Capitán- en el de Felipe II. De tal modo, la defensa cerrada de la justicia y el ataque al poder injusto no suponen en ningún momento el cuestionamiento del poder del rey que, por el contrario, resulta enaltecido como en las obras lopescas: El mejor alcalde, el rey, etc.

Las correlaciones que existen entre ambas obras podrían esquematizarse del siguiente modo:

CID / PEDRO CRESPO

ELVIRA Y SOL / INÉS Y LEONOR 
JESÚS FERNANDO CÁSEDA TERESA

\section{INFANTES DE CARRIÓN / HERMANOS \\ CAPITANES JUAN Y DIEGO \\ REY ALFONSO VI / REY FELIPE II \\ ROBLEDAL DE CORPES / ROBLE DE PEDRO CRESPO}

Cuando Calderón adapte El alcalde de Zalamea, se dedicará a simplificar el esquema cidiano, lo que significa acabar con él: de dos hijas a una sola; de dos capitanes a uno; ninguna referencia al robledal, etc. Pero, a pesar de lo que pudiera parecer, Calderón asume dicho esquema profundizando y dándole una visión más honda, adaptada al pensamiento barroco: mismo orden espiritual, moral, social y político. Los personajes de Calderón están mucho más desarrollados psicológicamente que los del primitivo autor y ofrecen una mayor complejidad, sin duda. Pero existe la influencia de El alcalde de Zalamea primitivo sobre el texto posterior.

Según el profesor Juan B. Martínez Benmecker,

[...] a la luz de la lectura de ambas comedias, salta a la vista el débito de Calderón a Lope, no de algún motivo o idea argumental, sino del cuerpo de la obra. Como ya resaltó Menéndez Pelayo (1949), Calderón reelabora el drama de Lope, haciéndolo distinto en todo lo esencial, aunque semejante en lo accidental: introduce innovaciones en la estructura de la obra, en el número y caracteres de los personajes y en las situaciones dramáticas, obedeciendo a criterios estéticos diferentes, en los que prevalece la claridad lógica, por la que se unifica la acción y los personajes principales adquieren mayor relieve. De los dos temas desarrollados en el primer Alcalde (el honor y el ejercicio de la justicia como alcalde de Zalamea), Calderón se queda sólo con uno, el honor, haciendo converger en él todos los elementos estructurales de la comedia, convertida así en un drama de honor ${ }^{10}$.

María Teresa Julio ha estudiado la presencia del Cid en el teatro de los siglos de Oro, y en general en todo el teatro español. Separa hasta cinco ciclos de teatro cidiano, siendo el quinto el que denomina de "las hijas del Cid", origen de obras como El honrador de sus hijas (1605) de Francisco Polo. Se trataría de la fuente más

${ }^{10}$ Martínez Bennecker, "Creación y recreación de El alcalde de Zalamea", Tonos Digital. Revista electrónica de estudios filológicos, 24, 2013. Disponible en línea en:

https://www.um.es/tonosdigital/znum24/secciones/estudios-20-el_alcalde_de_zalamea.htm.

[Fecha de consulta: 7 de septiembre de 2018]. 
Los dos Alcaldes de Zalamea. Del texto primitivo a la obra de Calderón...

próxima, en el tiempo, que trata el tema de la afrenta del Corpes de El alcalde de Zalamea, apenas escrita cinco años después de la publicación de la obra de Polo. En esta última encontramos algunos de los ingredientes que el primer autor de El alcalde de Zalamea desarrollará en su obra.

Como dice la investigadora citada, María Teresa Julio:

En una sociedad tan preocupada por los linajes y la limpieza de sangre, como apunta Egido (1994), la imagen del Cid, que aúna nobleza en la sangre y en las acciones, resulta muy atractiva. Si a ello añadimos que la tradición de los romances estaba viva y era perfectamente conocida por todos (con lo cual el éxito en los corrales estaba garantizado) y añadimos también las modificaciones que se introducen para adaptar el personaje a su época a fin de hacerlo contemporáneo, el resultado no podía ser otro que la imagen del Cid desde todos los ángulos: juventud, madurez, mitificación, parodia, endiosamiento, ridiculización, etc. Además, en la historia del Cid, o mejor en sus romances historiados, aparecen los ejes temáticos del teatro universal: amor, poder, traición, honor y celos ${ }^{11}$.

Cierto es que, con el tiempo, el tema cidiano se iría agotando y se resolvería en situaciones paródicas, ofreciendo un Cid ridiculizado, burlesco e incluso caricaturizado, como señala el profesor Ignacio Arellano (2007: 118):

[...] curiosamente destaca en versiones burlescas, cuya eficacia quizá deberíamos atribuir, no tanto al cansancio de la repetición, sino a la capacidad intrínseca de un tema heroico para ser vuelto al revés en forma de parodia.

En cualquier caso, el tema cidiano desaparecerá del teatro del XVIII español y reaparecerá nuevamente a impulsos del Romanticismo decimonónico, en su conocida recuperación de los temas medievales y de los personajes de aquel periodo histórico, a sus ojos atractivísimo.

11 "La mitologización del Cid en el teatro español". Disponible en línea en: https://cvc.cervantes.es/literatura/aih/pdf/13/aih_13_4_016.pdf. [Fecha de consulta: 7 de septiembre de 2018]. 


\section{JESÚS FERNANDO CÁSEDA TERESA}

\section{Conclusiones}

A lo largo de este estudio, creo haber descubierto algunas interesantes circunstancias literarias e históricas del primitivo Alcalde de Zalamea, fuente fundamental del texto calderoniano y haber establecido algunas relaciones de interés entre ambas obras. En resumen, serían las siguientes:

1. He llevado a cabo un estudio de los espacios históricos en que se desarrollan el primitivo texto y el de Calderón, y concluyo que se sitúan en dos Zalameas diferentes. El primer texto ha de localizarse en la luego llamada Zalamea la Real en la provincia de Huelva — en el tiempo histórico de la obra todavía solo Zalamea - por diversas razones que he referido: alusión a Bartolo el de Berrocal — localidad próxima a aquella_- presencia del personaje Juan Serrano - que entonces era el alcalde ordinario de la localidad-, momento histórico en que pasa a ser realengo y primeras luchas contra el poder real en defensa de la autonomía del alcalde ordinario. A partir de ahí, establezco una hipótesis: la posibilidad de que el primer autor escribiera la obra por encargo del concejo por haber conseguido entonces su estatuto de "real". Ello quizás explique la escritura un tanto apresurada de la obra y ciertos errores que ha detectado la crítica en el texto primitivo. No obstante, reconozco que ello no pasa de ser una hipótesis sin una prueba documental, y solo apoyada en las circunstancias históricas que señalo y en el hecho de que en la obra primitiva existen, como ha indicado la crítica, algunas tachas debidas a una posible escritura precipitada, quizás a causa de la premura en su elaboración por tratarse de un encargo, sujeto a unos plazos de entrega.

2. En el caso de la obra de Calderón, el espacio se sitúa con claridad en la provincia pacense, en Extremadura, en Zalamea de la Serena. Las referencias a Guadalupe o a Llerena son muy elocuentes a este respecto.

3. No obstante, establezco que quizás el primer autor fuera conocedor de la legendaria y falsa etimología que relacionaba el origen de Zalamea con el nombre del rey y juez bíblico Salomón, que ha pervivido hasta nuestros días. En todo caso, esa referencialidad a la ley y a la justicia es precisamente la que vertebra la estructura teatral de la obra: en Zalamea Pedro Crespo impartirá justicia como corresponde a un lugar y a un pueblo acostumbrado a ello.

4. En lógica correspondencia, los tiempos históricos de ambas obras son diferentes. La primitiva obra sitúa la acción con posterioridad al texto calderoniano. Si la de Calderón tiene lugar durante los preparativos anteriores a la entrada en Portugal, la otra se sitúa dos años después, una vez se ha anexionado el territorio peninsular portugués y la nueva expedición se dirige a Lisboa, atravesando Zalamea la Real, en Huelva, para embarcar en las naves hacia las Azores y luchar contra los franceses, una vez preparadas en Sevilla. 
Los dos Alcaldes de Zalamea. Del texto primitivo a la obra de Calderón...

5. Sitúo en el estudio el origen del personaje de Pedro Crespo, siempre ligado a su oficio de alcalde ordinario frente a la justicia de las audiencias o chancillerías, al alcance estas últimas de muy pocos. Es en el Gurmán de Alfarache donde encontramos su origen más evidente, y también en el Martín Crespo del Pedro de Urdemalas cervantino. Analizo también la importancia de la justicia impartida por los alcaldes ordinarios y el gran favor popular que alcanzaron. Sin embargo, descubro cierta ironía en el hecho de que el real alcalde ordinario de la localidad fuera entonces Juan Serrano, que también aparece como personaje en la obra, el cual fue tiempo después ajusticiado por morisco. Resulta bastante irónico el hecho de que el defensor a ultranza de su honra tuviera unos orígenes curiosamente manchados. Irónica es también la onomástica de sus hijas: Leonor que resulta deshonrada o sin honor, e Inés cuyo significado en griego sería 'casta y pura'.

6. No menos irónico resulta el trasunto real de los dos capitanes de la obra, Juan y Diego, probablemente los hermanos Fernández de Córdoba, con iguales apellidos que el Gran Capitán, que aparecen como miembros de los tercios que entraron en Portugal en reclamación de los derechos dinásticos de Felipe II.

7. Analizo cómo el texto primitivo toma de la tradición cidiana la estructura, la configuración de los personajes y algunos motivos interesantes. Lo resumo en el siguiente esquema:

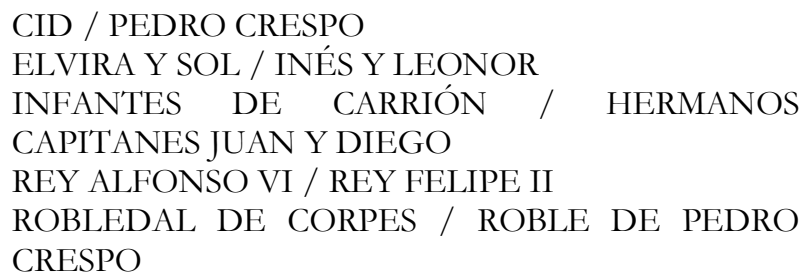

Quizás el reciente descubrimiento - finales del siglo XVI- del manuscrito de Santa Clara en Vivar (Burgos) por el enviado de Gil Ramírez de Arellano, Juan Ruiz de Ulibarri y Leyva, pero especialmente la relevante influencia que la tradición cidiana — vía romances y literatura popular - tenía sobre el teatro áureo, animó al primer autor a idear una estructura muy parecida a la de la obra medieval. En todo caso, Rodrigo Díaz de Vivar se convirtió en el mejor ejemplo de honor, limpieza de sangre, caballerosidad y virtudes cristianas. Y los dramas de honor - y El alcalde de Zalamea lo es - fueron los más cultivados en los Siglos de Oro españoles. No extraña por ello que el Cid sea protagonista en al menos veintidós obras teatrales conservadas de la época. 
JESÚs FERNANDO CÁSEDA TERESA

\section{Referencias bibliográficas}

Alemán, Mateo, Guzmán de Alfarache (edic. Benito Brancaforte). Madrid: Akal, 1996.

ARELlano, Ignacio, "El Cid en el teatro español del siglo de Oro". En: Cuadernos de Teatro Clásico, 23, 2007 (Ejemplar dedicado a: El Cid: poesía y teatro, José $\mathrm{M}^{\mathrm{a}}$ Díaz Borque (dir.), Mar Zubieta (ed.lit.), pp. 73-121.

ARJONA, J. Homero, "False andalusian rhymes in Lope de Vega and their bearing on the authorship of doubtful comedias". En: Hispanic Review, XXIV, 1956, pp. 290-305.

CAlderón De la BArCA Pedro; Vega, Lope de, El alcalde de Zalamea, (ed. de Juan Alcina Franch). Barcelona: Juventud, 1970.

_- El alcalde de Zalamea, (edición crítica de las dos versiones de Juan M. Escudero Baztán). Madrid: Iberoamericana, 1998.

CANTALAPIEDRA EROSTARBE, Fernando, El infanzón de Illescas y las comedias de Claramonte. Kassel: Reichenberger/Universidad de Granada, 1990.

__ El teatro de Claramonte y La estrella de Sevilla. Kassel: Reichenberger, 1993.

ESCUDERO BAZTÁN, Juan Manuel, "La construcción del mito del buen militar: historia y funcionalidad dramática en Don Lope de Figueroa". En: Neophilologus, vol. 98, 2, 2014, pp. 259-274.

FERnÁNDEZ Álvarez, Manuel, Felipe II y su tiempo. Madrid: Espasa, 1999.

FORNERON, Henri, Historia de Felipe II. Barcelona: Montaner y Simon Editores, 1884.

GONZÁLEZ RuIZ, F., "El alcalde de Zalamea". En: Revista de Feria, Huelva: Edición Católica Española, 1952.

GORDÓN PERAL, M. D., "Análisis etimológico de la macrotoponimia onubense". Disponible en línea en:

rabida.uhu.es/dspace/bitstream/handle/10272/2924/b15138677.pdf?seque nce $=1$. [Fecha de consulta: 7 de septiembre de 2018].

HENDRIKS, Victorinus, "Don Lope de Figueroa, figura histórica e imagen literaria". En: Actas del VIII Congreso de la Asociación Internacional de Hispanistas: 22-27 de agosto de 1983, 1984, pp. 703-708. Disponible en línea en: https://cvc.cervantes.es/literatura/aih/pdf/08/aih_08_1_075.pdf. [Fecha de consulta: 7 de septiembre de 2018].

Julio, María Teresa, "La mitologización del Cid en el teatro español". Disponible en línea en:

https://cvc.cervantes.es/literatura/aih/pdf/13/aih_13_4_016.pdf. [Fecha de consulta: 7 de septiembre de 2018]. 
Los dos Alcaldes de Zalamea. Del texto primitivo a la obra de Calderón...

KERNSTEN, Raquel, "El alcalde de Zalamea y su refundición por Calderón". En: Rizel Pincus Sigele y Gonzalo Soberano (eds.), Homenaje a Casalduero, crítica y poesía. Madrid: Gredos, 1972, pp. 263-273.

LEONARDI, Salvatore, "Para una biografía de Lope de Figueroa: Notas críticas y nuevas aportaciones. Parte primera: Hasta la jornada de Djerba y el final de su cautiverio por los turcos". En: Revista de Historia Militar, 114, 2013, pp. 273284.

LORENZANA, Felipe, "Jueces y pleitos. La administración de la justicia en la Baja Extremadura en el Antiguo Régimen”. En: Hispania, LXIII, 213, 2003, pp. 29 74.

MARTínez BenNeCKer, Juan B., "Creación y recreación de El alcalde de Zalamea". En: Tonos Digital. Revista electrónica de estudios filológicos, 24, 2013. Disponible en línea en: https://www.um.es/tonosdigital/znum24/secciones/estudios-20el_alcalde_de_zalamea.htm. [Fecha de consulta: 7 de septiembre de 2018].

MontAner Frutos, Alberto, "El Cid: mito y símbolo". En: Boletín del Museo e Instituto Camón Aznar, XXVII, 1987, pp. 121-340.

Morley, Griswold; Bruerton, Courtney, Cronología de las comedias de Lope de Vega. Madrid: Gredos, 1968.

PEALE, George, "Celebración, comprensión y subversión de la historia en el teatro aurisecular: el caso de Luis Vélez de Guevara". En: Luis Vélez de Guevara y su época. IV Congreso de historia de Écija (Écija, 20-23 de octubre de 1994). Sevilla: Ayuntamiento de Écija-Fundación El Monte, 1996, pp. 27-62.

RODRÍGUEZ LÓPEZ-VÁZQUEZ, Alfredo, "La estrella de Sevilla y Claramonte". En: Criticón, 21, 1983, pp. 5-31.

—- Andrés de Claramonte y El burlador de Sevilla. Kassel: Reichenberger, 1987a. - "Aportaciones críticas a la autoría de El burlador de Sevilla". En: Criticón, 40, 1987b, pp. 5-44.

(ed.), El alcalde de Zalamea. Reichenberger. Teatro del Siglo de Oro. Ediciones Críticas, 196, Kassel, 2014.

SAlAZAR y CASTRO, Luis, Historia genealógica de la Casa de Silva. Madrid: Melchor Alvarez y Mateo de Llanos, 1685.

SIMÓN DíAZ, José, Bibliografía de la literatura hispánica. Madrid: CSIC, 1994.

SuÁREZ INCLÁN, Julián, Guerra de anexión en Portugal durante el reinado de don Felipe II. Madrid: Imprenta y Litografía del depósito de la Guerra, 1898.

TiBÓN, G., Diccionario etimológico de nombres propios de persona. México: Unión Tipográfica Editorial Hispano-Americana, 1956.

TOURON DE RUIZ, Mercedes, “El alcalde de Zalamea en Lope y Calderón”. En: Cuadernos hispanoamericanos, 372, 1981, pp. 534-550. 
JESÚs FERnANDo CÁSEDA TERESA

TREXLER, Elizabeth E., "La cuestión de honor en las dos versiones de El alcalde de Zalamea". S.l. 2009. Disponible en línea en:

https://cdr.lib.unc.edu/indexablecontent/uuid:8d243675-2b23-4b45-8982b07e45474779. [Fecha de consulta: 7 de septiembre de 2018].

VALLADARES, Rafael, La conquista de Lisboa: violencia militar y comunidad politica en Portugal. Barcelona: Marcial Pons (Historia), 2008.

VÁZQUEZ, Luis, “Andrés de Claramonte (¿1580?-1626), la Merced, Tirso de Molina y El burlador de Sevilla (anotaciones críticas ante un intento de usurpación literaria)". En: Estudios, 151, 1985, pp. 397-429.

, "Documentos toledanos y madrileños de Claramonte y reafirmación de Tirso como autor de El burlador de Sevilla y convidado de piedra". En: Estudios, 156-157, 1987, pp. 9-50.

Vega García-Luengos, Germán, "El Cid en el teatro del Siglo de Oro español. Las múltiples caras de una figura persistente". Disponible en línea en:

https://uvadoc.uva.es/bitstream/10324/3756/1/Libro\%20CID.\%20Cap\% 202\%20G.Vega.pdf. [Fecha de consulta: 7 de septiembre de 2018].

WiENSBERGER, Markus, "El alcalde de Zalamea y los conceptos del orden y de la justicia", Disponible en línea en: http://www.markuswirnsberger.de/media/dd6aed4aa15b4b71ffff8b3cac144225.pdf. [Fecha de consulta: 7 de septiembre de 2018]. 